\title{
The Establishment of Decision Making Support Tool for Inventory Control and Production Planning with Periodic Review System and Linear Programming Approach
}

\author{
Redy Ardiansyah ${ }^{* 1}$, I Nyoman Pujawan ${ }^{2}$, and Niniet Indah Arvitrida ${ }^{2}$ \\ ${ }^{1}$ Department of Management Technology, Institut Teknologi Sepuluh Nopember, Indonesia \\ ${ }^{2}$ Department of Industrial Engineering, Institut Teknologi Sepuluh Nopember, Indonesia \\ e-mail: redy.mmt17@icloud.com
}

\begin{abstract}
PT. Mortars is an instant cement producer with many product variants. Some problems that $\mathrm{PT}$. Mortars encountered are uncertainty of demand, limitation on production capacity, and inventory capacity, which caused product shortages and high inventory costs. The production scheduling process is produced manually so it requires a long time, relying on the ability and experience of the production planner which is vulnerable to mistakes. Therefore, new methods and tools are needed for inventory control and production scheduling to make sure goods are delivered to customer just in time while maintaining operational efficiency. Periodic review system (R,S) and $(R, s, S)$ methods are proposed in this study to improve inventory parameters and reorder systems that have an impact on service levels and inventory costs. The tools are designed using Microsoft Excel software with solver add-ins functions and linear programming approaches to generate optimal production schedule decisions automatically. In order to determine the level of service and inventory costs generated by each method, a simulation is conducted by using the tools that have been made. The simulation of the existing method produces a service level of $98,64 \%$ and a total inventory cost of $R p$. 1.167.160.494. The periodic review system $(R, S)$ method resulted in increasing service level of $0,96 \%$ and lower inventory cost of $R p$. 15.130.801 while the periodic review system $(R, s, S)$ method resulted in increasing service level of $1,29 \%$ and a lower inventory cost of $R$ p. 448.653 compared to the existing method. The periodic review system $(R, S)$ method produces the lowest inventory costs while the method $(R, s, S)$ produces the highest service level compared to other methods.
\end{abstract}

Keywords-Production Planning and Inventory Control, Periodic Review System (R, S), (R, s, S), Linear Programming.

\section{INTRODUCTION}

$\mathrm{I}_{\mathrm{s}}^{\mathrm{s}}$ $\mathrm{N}$ the globalization era, companies that have reliable supply chain management will survive and win business competition. Although companies can produce good quality products at low prices, but the availability of products on the market is not guaranteed, then the customer will switch to competitor products or substitute products [1]. Uncertainty of demand is one of the problem faced by the company in meeting customer demands. To solve this problem, efficiency along the supply chain path is needed. So it takes inventory control planning and production scheduling in order to minimize production costs and improve service levels [2].

Good inventory management is needed to reduce the risk of demand uncertainty. In businesses that use make-to-stock operating system, efficient inventory management is very
Table 1

Inventory Days of Supply Parameters

\begin{tabular}{cccc}
\multicolumn{4}{c}{ Inventory Days of Supply Parameters } \\
\hline Products & $\begin{array}{c}\text { Demand } \\
\text { average }\end{array}$ & $\begin{array}{c}\text { Inventory } \\
\text { days }\end{array}$ & $\begin{array}{c}\text { Order Up to } \\
\text { level }\end{array}$ \\
\hline Units & bag/ day & Days & Bag \\
Total & 15.260 & & 61.344 \\
MR-200-20KG & 568 & 6 & 3.408 \\
MR-200-40KG & 601 & 6 & 3.606 \\
MR-202-40KG & 462 & 6 & 2.772 \\
MR-250-40KG & 762 & 6 & 4.572 \\
MR-270-25KG & 98 & 15 & 1.470 \\
MR-272-40KG & 231 & 6 & 1.386 \\
MR-290-40KG & 118 & 8 & 944 \\
MR-100-40KG & 251 & 5 & 1.255 \\
MR-101-40KG & 14 & 6 & 84 \\
MR-301-40KG & 1.161 & 2 & 2.322 \\
MR-302-50KG & 4.614 & 3 & 13.842 \\
MR-380-40KG & 2.227 & 3 & 6.681 \\
MR-382-40KG & 727 & 3 & 2.181 \\
MR-400-25KG & 1.395 & 3 & 4.185 \\
MR-402-40KG & 258 & 5 & 1.290 \\
MR-410-25KG & 10 & 30 & 300 \\
MR-420-25KG & 411 & 4 & 1.644 \\
MR-422-40KG & 51 & 6 & 306 \\
MR-440-40KG & 26 & 15 & 390 \\
MR-440-50KG & 443 & 4 & 1.772 \\
MR-443-40KG & 93 & 2 & 186 \\
MR-445-40KG & 29 & 15 & 435 \\
MR-450-40KG & 316 & 4 & 1.264 \\
MR-460W-25KG & 69 & 15 & 1.035 \\
MR-480-25KG & 148 & 6 & 888 \\
MR-485-25KG & 48 & 4 & 192 \\
MR-700-25KG & 27 & 30 & 810 \\
MR-800-20KG & 50 & 30 & 1.500 \\
MR-830-40KG & 46 & 12 & 552 \\
MR-840-25KG & 6 & & 72 \\
\hline \hline
\end{tabular}

important. This is because the inventory along the supply chain path has major implications for company's financial performance [3]. The amount of inventory is usually very large, even the value exceeds $25 \%$ of the total value of assets held. To keep the inventory level at the desired amount, it needs to balance the supply and demand. Mathematical models programming plays a very important role in the scenario of inventory control strategies and production scheduling, [4]. With optimal inventory control and production scheduling, product availability and operational efficiency can be achieved in accordance with existing 
The $1^{\text {st }}$ International Conference on Business and Engineering Management (IConBEM)

February $1^{\text {st }} 2020$, Institut Teknologi Sepuluh Nopember, Surabaya, Indonesia

Table 2

Order Up to Level (S) Parameters

\begin{tabular}{|c|c|c|c|}
\hline Products & $\begin{array}{l}\text { Demand } \\
\text { average }\end{array}$ & $\begin{array}{l}\text { Safety } \\
\text { Stock }\end{array}$ & $\begin{array}{l}\text { Order up to } \\
\text { level }\end{array}$ \\
\hline Units & bag/ day & Days & Bag \\
\hline Total & 18.469 & 21.689 & 60.177 \\
\hline MR-200-20KG & 863 & 1.230 & 6.456 \\
\hline MR-200-40KG & 564 & 1.207 & 4.618 \\
\hline MR-202-40KG & 649 & 622 & 4.551 \\
\hline MR-250-40KG & 899 & 841 & 6.304 \\
\hline MR-270-25KG & 134 & 220 & 1.027 \\
\hline MR-272-40KG & 231 & 373 & 1.765 \\
\hline MR-290-40KG & 138 & 283 & 1.114 \\
\hline MR-100-40KG & 468 & 564 & 1.050 \\
\hline MR-101-40KG & 122 & 150 & 274 \\
\hline MR-301-40KG & 1.055 & 1.505 & 2.636 \\
\hline MR-302-50KG & 5.383 & 3.418 & 10.553 \\
\hline MR-380-40KG & 2.194 & 2.722 & 5.219 \\
\hline MR-382-40KG & 850 & 878 & 1.779 \\
\hline MR-400-25KG & 1.519 & 2.296 & 3.943 \\
\hline MR-402-40KG & 459 & 475 & 951 \\
\hline MR-410-25KG & 49 & 89 & 139 \\
\hline MR-440-40KG & 139 & 262 & 265 \\
\hline MR-440-50KG & 589 & 877 & 906 \\
\hline MR-443-40KG & 93 & 74 & 75 \\
\hline MR-445-40KG & 133 & 252 & 254 \\
\hline MR-450-40KG & 306 & 401 & 410 \\
\hline MR-460W-25KG & 120 & 150 & 154 \\
\hline MR-480-25KG & 203 & 296 & 301 \\
\hline MR-485-25KG & 48 & 69 & 70 \\
\hline MR-700-25KG & 192 & 489 & 493 \\
\hline MR-800-20KG & 211 & 415 & 420 \\
\hline MR-830-40KG & 102 & 130 & 132 \\
\hline MR-840-25KG & 21 & 44 & 44 \\
\hline MR-420-25KG & 577 & 1.061 & 1.660 \\
\hline MR-422-40KG & 158 & 296 & 457 \\
\hline MR-440-40KG & 139 & 262 & 404 \\
\hline MR-440-50KG & 589 & 877 & 1.495 \\
\hline MR-443-40KG & 93 & 74 & 168 \\
\hline MR-445-40KG & 133 & 252 & 387 \\
\hline MR-450-40KG & 306 & 401 & 716 \\
\hline MR-460W-25KG & 120 & 150 & 274 \\
\hline MR-480-25KG & 203 & 296 & 504 \\
\hline MR-485-25KG & 48 & 69 & 118 \\
\hline MR-700-25KG & 192 & 489 & 685 \\
\hline MR-800-20KG & 211 & 415 & 631 \\
\hline MR-830-40KG & 102 & 130 & 234 \\
\hline MR-840-25KG & 21 & 44 & 65 \\
\hline
\end{tabular}

constraints. PT. Mortars is an instant cement producer which has 2 production lines called the large bag production line (instant cement) and the small bag production line (tile grout). This research is focused on the large bag production line with 30 product types, which are divided into 2 types of product groups, namely plaster and adhesive (sand product) and skimcoat (non sand product). For each product changeover (set-up), the production line must be cleaned around 10 minutes, except for the initial change of plaster and adhesive product to the skimcoat product which takes 120 minutes (according to the standard quality procedure).

PT. Mortars has a warehouse capacity that can accommodate up to 70,000 bags and a production capacity of 21,000 bags / day. The average daily demand of PT. Mortars is $15,000 \mathrm{bags} /$ day. Production capacity and storage capacity will be a constraint for PT. Mortars in fulfillment of customer demand. Inventory control of PT. Mortars should be efficient
Table 3.

Re-Order Point (s) Parameters

\begin{tabular}{cccc}
\hline \hline Products & $\begin{array}{c}\text { Average } \\
\text { demand }\end{array}$ & $\begin{array}{c}\text { Safety } \\
\text { Stock }\end{array}$ & $\begin{array}{c}\text { Re-order } \\
\text { point }\end{array}$ \\
\hline units & bag/ day & Bag & bag \\
MR-200-20KG & 18.469 & 21.689 & 24.318 \\
MR-200-40KG & 863 & 1230 & 1278 \\
MR-202-40KG & 564 & 1207 & 1234 \\
MR-250-40KG & 649 & 622 & 657 \\
MR-270-25KG & 899 & 841 & 910 \\
MR-272-40KG & 134 & 220 & 223 \\
MR-290-40KG & 138 & 373 & 379 \\
MR-100-40KG & 468 & 283 & 286 \\
MR-101-40KG & 122 & 564 & 582 \\
MR-301-40KG & 1055 & 150 & 152 \\
MR-302-50KG & 5383 & 1505 & 1581 \\
MR-380-40KG & 2194 & 3418 & 5170 \\
MR-382-40KG & 850 & 2722 & 3025 \\
MR-400-25KG & 1519 & 878 & 929 \\
MR-402-40KG & 459 & 2296 & 2424 \\
MR-410-25KG & 49 & 475 & 492 \\
MR-420-25KG & 577 & 89 & 90 \\
MR-422-40KG & 158 & 1061 & 1083 \\
\hline \hline
\end{tabular}

Table 4.

EPQ (Q) and Maximum Stock (S) Parameters

\begin{tabular}{|c|c|c|}
\hline Products & EPQ & Max stock \\
\hline Units & bag & Bag \\
\hline Total & 52.783 & 77.101 \\
\hline MR-200-20KG & 3.501 & 4.779 \\
\hline MR-200-40KG & 1.871 & 3.105 \\
\hline MR-202-40KG & 2.804 & 3.461 \\
\hline MR-250-40KG & 3.958 & 4.868 \\
\hline MR-270-25KG & 502 & 725 \\
\hline MR-272-40KG & 437 & 816 \\
\hline MR-290-40KG & 411 & 697 \\
\hline MR-100-40KG & 1.989 & 2.571 \\
\hline MR-101-40KG & 631 & 783 \\
\hline MR-301-40KG & 2.935 & 4.516 \\
\hline MR-302-50KG & 10.049 & 15.219 \\
\hline MR-380-40KG & 3.905 & 6.930 \\
\hline MR-382-40KG & 3.179 & 4.108 \\
\hline MR-400-25KG & 3.023 & 5.447 \\
\hline MR-402-40KG & 1.791 & 2.283 \\
\hline MR-410-25KG & 59 & 149 \\
\hline MR-420-25KG & 2.051 & 3.134 \\
\hline MR-422-40KG & 1.066 & 1.365 \\
\hline MR-440-40KG & 428 & 693 \\
\hline MR-440-50KG & 2.855 & 3.761 \\
\hline MR-443-40KG & 193 & 268 \\
\hline MR-445-40KG & 438 & 692 \\
\hline MR-450-40KG & 1.680 & 2.090 \\
\hline MR-460W-25KG & 293 & 447 \\
\hline MR-480-25KG & 572 & 873 \\
\hline MR-485-25KG & 163 & 233 \\
\hline MR-700-25KG & 565 & 1.058 \\
\hline MR-800-20KG & 881 & 1.301 \\
\hline MR-830-40KG & 440 & 572 \\
\hline MR-840-25KG & 113 & 157 \\
\hline
\end{tabular}

to reach the service level target with optimal costs. Difficulties faced by PT. Mortars are large product demand fluctuations and large product variants which are produced by using the same machine (single machine multi products).

To maintain the balance of inventory levels, PT. Mortars conducts replenishment by producing based on production 
The $1^{\text {st }}$ International Conference on Business and Engineering Management (IConBEM)

February $1^{\text {st }} 2020$, Institut Teknologi Sepuluh Nopember, Surabaya, Indonesia

Table 5.

Result of Manual Calculations (01/30/2019)

\begin{tabular}{|c|c|c|c|c|c|c|c|}
\hline Product code & $\begin{array}{l}\text { Order up } \\
\text { to level }\end{array}$ & $\begin{array}{l}\text { Initial } \\
\text { stock }\end{array}$ & Demand & $\begin{array}{l}\text { dInventory } \\
\text { level }\end{array}$ & $\begin{array}{l}\text { Re-order } \\
\text { quantity }\end{array}$ & $\begin{array}{l}r \text { Production } \\
\text { time needs }\end{array}$ & $\begin{array}{c}\begin{array}{c}\text { Priority } \\
\text { level }\end{array} \\
\end{array}$ \\
\hline Total product & 60177 & 53452 & 22296 & 31156 & 29021 & 31,6 & - \\
\hline MR-100-40KG & 1050 & 650 & 625 & 25 & 1025 & 1,1 & 11 \\
\hline MR-101-40KG & 274 & 39 & 75 & -36 & 310 & 0,3 & 5 \\
\hline MR-301-40KG & 2636 & 2636 & 3065 & -429 & 3065 & 3,4 & 2 \\
\hline MR-302-50KG & 10553 & 10553 & 4535 & 6018 & 4535 & 5,0 & 6 \\
\hline MR-380-40KG & 5219 & 4051 & 1765 & 2286 & 2933 & 3,2 & 8 \\
\hline MR-382-40KG & 1779 & 1779 & 1315 & 464 & 1315 & 1,4 & 10 \\
\hline MR-400-25KG & 3943 & 2580 & 2156 & 424 & 3519 & 3,2 & 7 \\
\hline MR-402-40KG & 951 & 331 & 936 & -605 & 1556 & 1,7 & 1 \\
\hline MR-420-25KG & 1660 & 1660 & 1500 & 160 & 1500 & 1,4 & 9 \\
\hline MR-422-40KG & 457 & 457 & 62 & 395 & 62 & 0,1 & 15 \\
\hline MR-440-40KG & 404 & 384 & 0 & 384 & 20 & 0,0 & 16 \\
\hline MR-440-50KG & 1495 & 385 & 557 & -172 & 1667 & 2,0 & 3 \\
\hline MR-443-40KG & 168 & 168 & 0 & 168 & 0 & - & - \\
\hline MR-445-40KG & 387 & 387 & 0 & 387 & 0 & - & - \\
\hline MR-450-40KG & 716 & 716 & 225 & 491 & 225 & 0,2 & 13 \\
\hline MR-480-25KG & 504 & 504 & 594 & -90 & 594 & 0,7 & 4 \\
\hline MR-700-25KG & 685 & 685 & 0 & 685 & 0 & - & - \\
\hline MR-800-20KG & 631 & 331 & 0 & 331 & 300 & 0,3 & 12 \\
\hline MR-830-40KG & 234 & 134 & 50 & 84 & 150 & 0,2 & 14 \\
\hline MR-840-25KG & 65 & 65 & 0 & 65 & 0 & - & - \\
\hline MR-485-25KG & 118 & 118 & 0 & 118 & 0 & - & - \\
\hline $\begin{array}{l}\text { MR-460W- } \\
25 \mathrm{KG}\end{array}$ & 274 & 274 & 0 & 274 & 0 & - & - \\
\hline MR-410-25KG & 139 & 139 & 0 & 139 & 0 & - & - \\
\hline
\end{tabular}

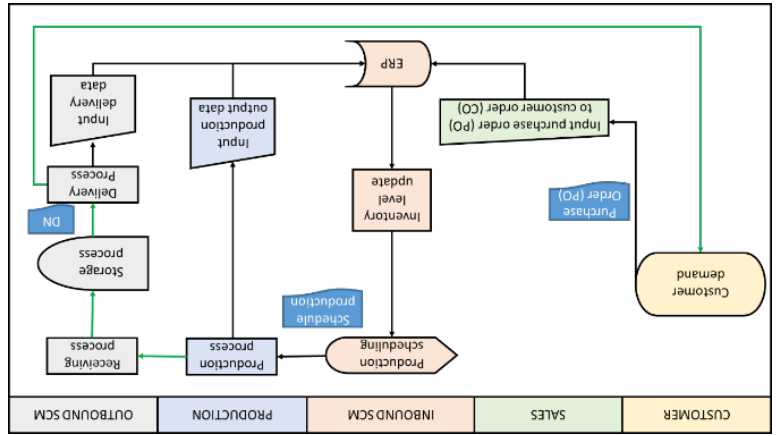

Figure 1. Inventory Control Data Flow Diagram.

schedule. Production scheduling at PT. Mortars are still manually so that it is less efficient, therefore distribution of production schedules is often late, frequent miss-scheduling (wrong in determining the quantity of products, typos, etc.) and relying on the ability and experience of the production planner. Production scheduling is done by allocating production time as needed and determining the production amount for each products.

From the explanation above, inventory control and production scheduling are important for PT. Mortars, so it is required for proper inventory control and production scheduling methods. The solution to overcome these problems is to design a decision making tool that combines inventory control and production scheduling methods. Application of right inventory control and production scheduling, will have an impact on optimal inventory costs and service levels in line with expectations.

The proposed inventory control method is the periodic review system $(R, S)$ and $(R, s, S)$ to determine the policy of replenishment mechanism and to improve the inventory

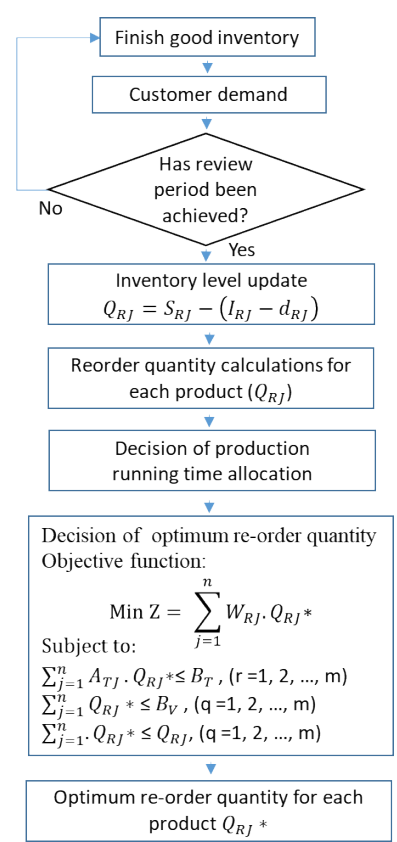

Figure 2. Proposed Production Scheduling Flow Chart.

parameters of PT. Mortars. In the proposed method there is consideration of safety stock to anticipate demand uncertainty. The linear programming method is used to produce optimal production scheduling in accordance with production capacity limits, storage capacity limits and production priorities. The tool is designed using Microsoft Excel software with the Solver Add-ins function. The scheduling process is no longer manual but has been computerized, so that the process of inventory control and production scheduling can be done quickly, precisely, standardized and minimize human error in the process.

\section{LITERATUR REVIEW}

To solve the problem described in the introduction, a inventory control with periodic review system method and production scheduling with linear programming approach is proposed.

According to Silver et al. [5], there are two methods of inventory control: continuous review (Q- system) and periodic review (T-system). There are 2 types of continuous review methods, $(\mathrm{s}, \mathrm{Q})$ and $(\mathrm{s}, \mathrm{S})$ methods. In the continous review method, replenishment of inventory is carried out if the inventory level has reached or lower than the reorder point (s), and the number of reorder quantity as much as Q. In method (s, Q), the reorder quantity (Q) will be ordered by economic production quantity (EPQ), while in method $(\mathrm{s}, \mathrm{S})$ the reorder quantity $(\mathrm{Q})$ will be ordered by a number of differences between maximum inventory $(\mathrm{S})$ and inventory level, where (S) is $\mathrm{s}+\mathrm{EPQ}$.

There are 2 types of periodic review methods, methods ( $R$, $S)$ and methods $(R, s, S)$. The method $(R, s, S)$ is a combination of the periodic review system $(R, S)$ and continuous review system $(\mathrm{s}, \mathrm{S})$. In the method $(\mathrm{R}, \mathrm{S})$ the reorder is carried out if the review period (R) has arrived, whereas in the method $(\mathrm{R}, \mathrm{s}, \mathrm{S})$ the reorder is carried out when the review period $(R)$ has arrived and the inventory level is smaller equals to the reorder point $(\mathrm{s})$. In the $(\mathrm{R}, \mathrm{S})$ and $(\mathrm{R}, \mathrm{s}$, $S$ ) methods reorder quantity $(\mathrm{Q})$ will be ordered by a number of differences between (S) and the inventory level. 
The $1^{\text {st }}$ International Conference on Business and Engineering Management (IConBEM)

February $1^{\text {st }} 2020$, Institut Teknologi Sepuluh Nopember, Surabaya, Indonesia

Table 6.

Simulation Results for The First Quarter of 2019

\begin{tabular}{|c|c|c|c|c|}
\hline \multicolumn{5}{|c|}{ Q1 2019 Period } \\
\hline \multirow[t]{2}{*}{ Description } & \multirow[t]{2}{*}{ Unit } & \multirow[t]{2}{*}{ Existing Method } & \multicolumn{2}{|c|}{ Periodic Review System Method. } \\
\hline & & & $\mathrm{R}, \mathrm{S}$ & $\mathrm{R}, \mathrm{s}, \mathrm{S}$ \\
\hline Start inventory level & Bag & 61.344 & 60.177 & 77.101 \\
\hline Total demand & Bag & 1.222 .032 & 1.222 .032 & 1.222 .032 \\
\hline Total production & Bag & 1.198 .226 & 1.206 .971 & 1.186 .077 \\
\hline Set-up frequency & $(x$ freq) & 587 & 607 & 298 \\
\hline Inventory average & Bag & 51.176 & 50.718 & 53.841 \\
\hline End inventory level & Bag & 36.590 & 45.116 & 41.146 \\
\hline \multicolumn{5}{|c|}{ Key Performance } \\
\hline Product shortage & Bag & $(16.648)$ & $(4.963)$ & $(834)$ \\
\hline Service level & $\%$ & $98,64 \%$ & $99,59 \%$ & $99,93 \%$ \\
\hline Utilization loss & hours & 1,62 & 1,62 & 12,35 \\
\hline \multicolumn{5}{|c|}{ Cost } \\
\hline Inventory cost & Rupiah & 322.099 .779 & 304.134 .294 & 309.604 .090 \\
\hline Set-up cost & Rupiah & 61.938 .062 & 63.634 .432 & 67.927 .547 \\
\hline Process cost & Rupiah & 764.488 .302 & 772.076 .736 & 764.730 .621 \\
\hline Inventory deviation cost & Rupiah & 18.634 .350 & 12.184 .231 & 25.346 .889 \\
\hline Total Cost & Rupiah & 1.167 .160 .494 & 1.152 .029 .693 & 1.167 .609 .147 \\
\hline
\end{tabular}

Table 7.

Februari 2019 Simulation Results

\begin{tabular}{|c|c|c|c|c|}
\hline \multicolumn{5}{|c|}{ February 2019 Period } \\
\hline \multirow[t]{2}{*}{ Description } & \multirow[t]{2}{*}{ Unit } & \multirow[t]{2}{*}{ Existing Method } & \multicolumn{2}{|l|}{ Periodic Review System Method. } \\
\hline & & & $\mathrm{R}, \mathrm{S}$ & $\mathrm{R}, \mathrm{s}, \mathrm{S}$ \\
\hline Start inventory level & Bag & 45.200 & 44.033 & 42.365 \\
\hline Total demand & Bag & 410.539 & 410.539 & 410.539 \\
\hline Total production & Bag & 401.641 & 403.045 & 414.220 \\
\hline Set-up frequency & (x freq) & 193 & 197 & 102 \\
\hline Inventory average & Bag & 51.098 & 49.787 & 54.600 \\
\hline \multirow[t]{2}{*}{ End inventory level } & Bag & 37.662 & 36.539 & 46.046 \\
\hline & & Key Performan & & \\
\hline Product shortage & Bag & $(5.141)$ & $(925)$ & - \\
\hline Service level & $\%$ & $98,75 \%$ & $99,77 \%$ & $100,00 \%$ \\
\hline \multirow[t]{2}{*}{ Utilization loss } & hours & 0 & 0 & 0 \\
\hline & & Cost & & \\
\hline Inventory cost & Rupiah & 97.560 .260 & 91.312 .856 & 97.605 .682 \\
\hline Set-up cost & Rupiah & 20.108 .310 & 20.447 .584 & 25.728 .472 \\
\hline Process cost & Rupiah & 263.951 .328 & 263.951 .639 & 272.533 .168 \\
\hline Inventory deviation cost & Rupiah & 5.167 .081 & 5.167 .125 & $(2.127 .489)$ \\
\hline Total Cost & Rupiah & 386.786 .979 & 380.879 .204 & 393.739 .833 \\
\hline
\end{tabular}

Table 8.

March Simulation Result

\begin{tabular}{|c|c|c|c|c|}
\hline \multicolumn{5}{|c|}{ March 2019 Period } \\
\hline Description & Unit & Existing Method & Periodic Review System Method. & \\
\hline & & & $\mathrm{R}, \mathrm{S}$ & $\mathrm{R}, \mathrm{s}, \mathrm{S}$ \\
\hline Start inventory level & Bag & 37.662 & 36.539 & 46.046 \\
\hline Total demand & Bag & 419.496 & 419.496 & 419.496 \\
\hline Total production & Bag & 420.732 & 428.073 & 414.596 \\
\hline Set-up frequency & (x freq) & 201 & 212 & 103 \\
\hline Inventory average & Bag & 51.316 & 51.299 & 51.440 \\
\hline End inventory level & Bag & 36.590 & 45.116 & 41.146 \\
\hline \multicolumn{5}{|c|}{ Key Performance } \\
\hline Product shortage & Bag & $(3.856)$ & $(1.943)$ & (834) \\
\hline Service level & $\%$ & $99,08 \%$ & $99,54 \%$ & $99,80 \%$ \\
\hline Utilization loss & hours & 0 & 0 & 0 \\
\hline \multicolumn{5}{|c|}{ Cost } \\
\hline Inventory cost & Rupiah & 107.242 .085 & 101.375 .353 & 101.080 .583 \\
\hline Set-up cost & Rupiah & 21.721 .443 & 22.654 .446 & 22.839 .898 \\
\hline Process cost & Rupiah & 271.332 .478 & 278.920 .621 & 269.818 .199 \\
\hline Inventory deviation cost & Rupiah & 1.057 .392 & $(5.392 .772)$ & 2.344 .389 \\
\hline Total Cost & Rupiah & 401.353 .398 & 397.557 .648 & 396.083 .069 \\
\hline
\end{tabular}

Optimization is one of the scientific disciplines in mathematics that focuses on getting the maximum or minimum values systematically from a function [6]. Optimization is needed by companies in order to optimize resources such as raw materials, labor and production facilities that are used so that the production process can produce products in the quantity and quality expected [7].
Linear Programming (LP) is one method in operations research that can be used for planning and decision making in allocating limited resources (constraints) to achieve company goals (objective function) such as maximizing profits or minimizing costs. The method represents the real world into a mathematical model consisting of a linear objective function and several linear constraints. Linear 
The $1^{\text {st }}$ International Conference on Business and Engineering Management (IConBEM)

February $1^{\text {st }} 2020$, Institut Teknologi Sepuluh Nopember, Surabaya, Indonesia

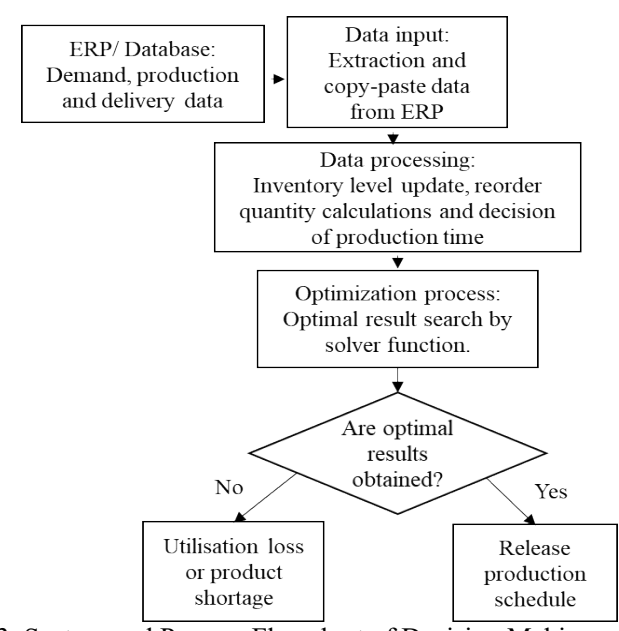

Figure 3. System and Process Flowchart of Decision Making.

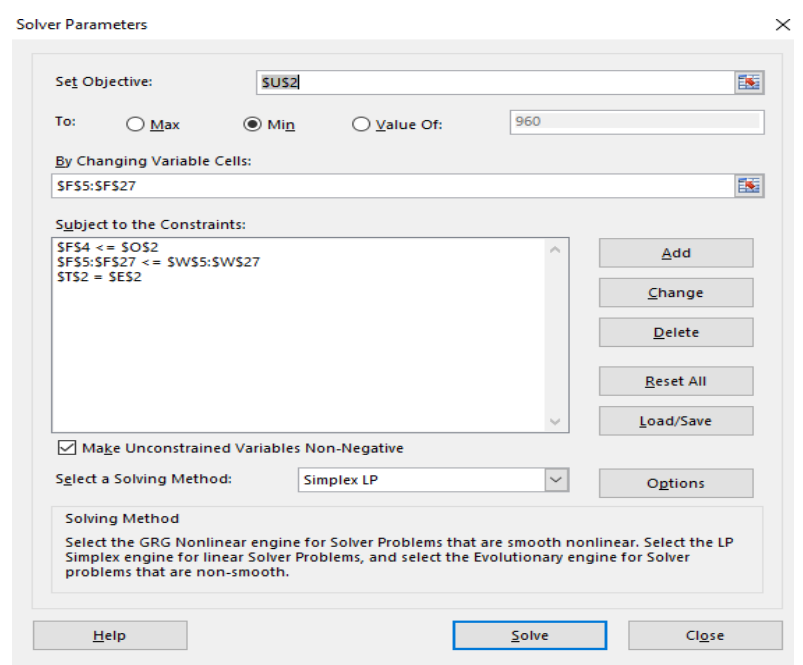

Figure 4. Running process of Solver Add-ins.

programming is widely applied in economic, industrial, military, social and others.

\section{METHODOLOGY}

After the problem definition and literature study are completed, the data collection is performed. Data of demand quantity, inventory costs and set-up costs will be processed into inventory parameter according to the calculation mechanism in the proposed method.

The next stage is the design of models and the development of decision making systems. At this stage a production scheduling decision making tool will be designed using Microsoft Excel software, using the Solver add-ins function. Decisions generated by tools are determined based on a linear programming approach so mathematical modeling is needed in accordance with the inventory control method used. After the tool has been designed, a numerical test is validated by comparing the results of manual calculations with the results of calculations using tools that are designed.

If the result of both calculations are match, then the tool can be declared reliable. The next step is the simulation of inventory control. The aim of this stage is to obtain the total cost and service level from each method. The simulation will be carried out by scheduling the daily production during the

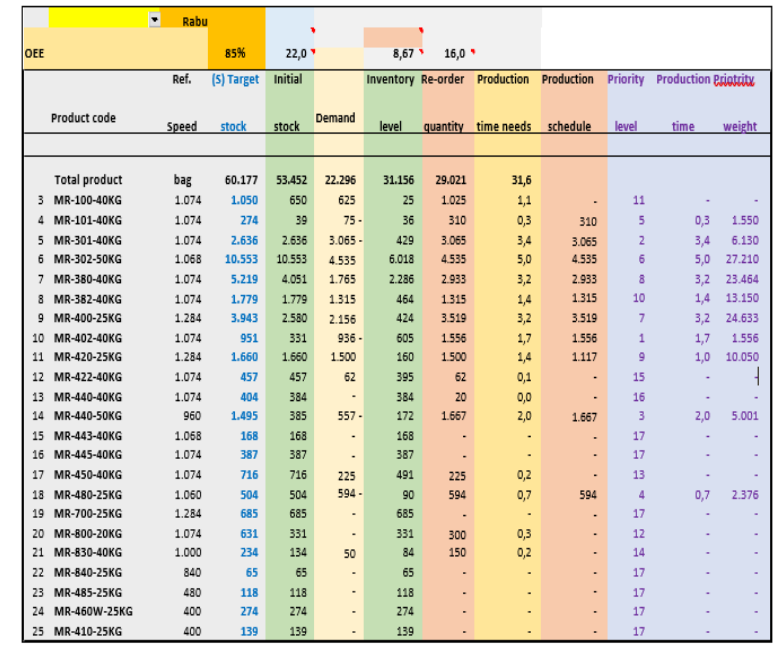

Figure 5. Example of Optimization Results Using Designed Tools (date: $01 / 30 / 2019)$

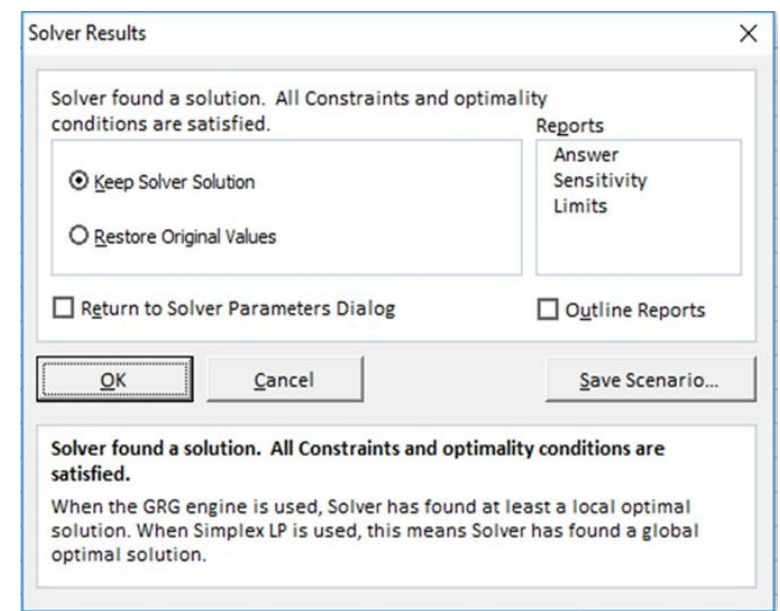

Figure 6. Example of Optimal Results Notification

first quarter period (Q1 2019). From the simulation results, an analysis and discussion is carried out to find out the method that produces the best total cost and service level. The results of this analysis will be concluded the right method to be used as a method of inventory control at Pt. Mortars. All the research results can be used to give suggestions for companies and further research.

\section{RESULT AND DISCUSSION}

\section{A. Data Collection}

At this stage, data collection is carried out in the form of data on the number of demand per product per day during the Q1 2019 period, inventory costs, set-up costs, processing costs, inventory deviation costs and the number of existing inventory parameters of PT. Mortars.

The value of storage costs is determined at $30 \%$ per year per bag or $2.5 \%$ per month per bag of the the product cost. The process cost is determined from the labor cost Rp. 249.711/ hours (12 operators) and energy costs Rp. 259.200/ hours. The process of changeover for similar products and skimcoat to adhesive products needs about 10 minutes with costs $\mathrm{Rp}$. 84,818 which consists of labor and energy costs that remains consumed during the changeover process. Especially for the changeover from plaster or adhesive to skimcoat products, cleaning for production lines must be carried out so that the 
The $1^{\text {st }}$ International Conference on Business and Engineering Management (IConBEM)

February $1^{\text {st }} 2020$, Institut Teknologi Sepuluh Nopember, Surabaya, Indonesia

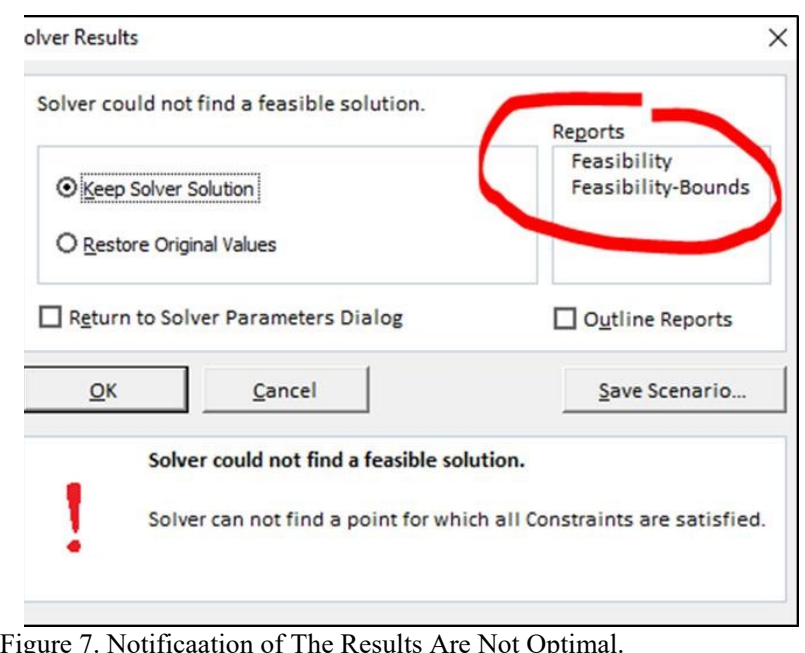

Figure 7. Notificaation of The Results Are Not Optimal.

skimcoat products is not contaminated by residual sand used during the production process of plaster or adhesive products (skimcoat cleaning). The cleaning process is carried out about 3 hours with 5 workers with cost of Rp 934,585 for a single cleaning process.

Inventory control policies currently used by PT. Mortras, almost resembles the periodic review system $(\mathrm{R}, \mathrm{S})$ method because the review period $(\mathrm{R})$ is done once a day. However, the target inventory value (S) does not use calculations according to the method $(\mathrm{R}, \mathrm{S})$, but uses the inventory days of supply policy for each product. The calculation mechanism to determine PT.Mortars' order up to level (S) is to take the biggest demand in a particular month in the previous year period, then it will be divided by 22 working days to obtain the daily demand average. The average will be multiplied by the amount of inventory should be owned in units of days determined based on the results of discussions between the SCM team and the operation manager. The parameters of the order up to level are as follows at Table 1.

\section{B. Data Processing}

After all the data needed for research is collected, then the data is processed to determine the inventory parameters in accordance with the proposed method. In the $(\mathrm{R}, \mathrm{S})$ method the parameter of review period $(R)$ is set at one day for the plaster and adhesive product and one week for the skimcoat product. The use of different review periods between plaster and adhesives products with skimcoat products is expected to reduce the cost of skimcoat clenaing. Inventory level parameters order up to level (S) are determined based on the following formula: $\mathrm{d} \times(1+\mathrm{R})+\mathrm{SS}$ (equation 1$)$,

with :

$\mathrm{d}=$ demand average $1=$ lead time

$\mathrm{R}=$ review period $\mathrm{SS}=$ safety stock

To calculate the value of safety stock, a service level of $95 \%$ is used. Leadtime is determined based on the production rate for each product. From the calculation based on the formula, the results of the calculation of the order up to level are obtained as follows Table 2

In the method $(\mathrm{R}, \mathrm{s}, \mathrm{S})$ the period of the review period $(\mathrm{R})$ used is one day for the adhesive product and the acian product. So that in this period skimcoat products can be produced every day. There are 2 parameters of the target inventory, namely reorder point (s) and maximum inventory (S). This is what distinguishes the method $(\mathrm{R}, \mathrm{s}, \mathrm{S})$ and the

\begin{tabular}{|c|c|c|c|}
\hline \multicolumn{4}{|c|}{$\begin{array}{l}\text { Microsoft Excel 15.0 Feasibility Report } \\
\text { Worksheet: [Periodic review- Dact rev4 - Copy.xlsx]solver-Plaster } \\
\text { Report Created: 12/05/2019 17.59.49 }\end{array}$} \\
\hline \multicolumn{4}{|c|}{ Constraints Which Make the Problem Infeasible } \\
\hline Name & Cell Value & Formula & Status \\
\hline \$F\$5 MU-100-40KG Prod Schedule & $200 \$$ & $F \$ 5<=\$ W \$ 5$ & Binding \\
\hline \$F\$6 MU-101-40KG Prod Schedule & & $F \$ 6<=\$ W \$ 6$ & Binding \\
\hline \$F\$7 MU-301-40KG Prod Schedule & $120 \$$ & $F \$ 7<=\$ W \$ 7$ & Binding \\
\hline \$F\$8 MU-302-50KG Prod Schedule & 8355 & $F \$ 8<=\$ W \$ 8$ & Binding \\
\hline \$F\$9 MU-380-40KG Prod Schedule & $2200 \$$ & $F \$ 9<=\$ W \$ 9$ & Binding \\
\hline \$F\$10 MU-382-40KG Prod Schedule & $1288 \$ F$ & $\$ 10<=\$ W \$ 10$ & Binding \\
\hline \$F\$11 MU-400-25KG Prod Schedule & $200 \$ F$ & $\$ 11<=\$ W \$ 11$ & Binding \\
\hline \$F\$12 MU-402-40KG Prod Schedule & $1135 \$$ & $\$ 12<=\$ W \$ 12$ & Binding \\
\hline \$F\$13 MU-420-25KG Prod Schedule & $0 \$ F$ & $\$ 13<=\$ W \$ 13$ & Binding \\
\hline \$F\$14 MU-422-40KG Prod Schedule & $0 \$ F$ & $\$ 14<=\$ W \$ 14$ & Binding \\
\hline$\$ F \$ 15$ MU-440-40KG Prod Schedule & $0 \$ F$ & $\$ 15<=\$ W \$ 15$ & Binding \\
\hline
\end{tabular}

method $(\mathrm{R}, \mathrm{S})$. To determine the reorder point parameter (s), the following formula is used:

$\mathrm{ROP}(\mathrm{s})=\mathrm{d} \times 1+\mathrm{SS}$ (equation 2 )

with:

$\mathrm{d}=$ average demand $\mathrm{l}=$ lead time

$\mathrm{SS}=$ safety stock

The safety stock and leadtime values used are the same as the method $(\mathrm{R}, \mathrm{S})$. From the calculations performed the following results are obtained:

The maximum inventory value $(\mathrm{S})$ is the sum of the reorder point (s) and EPQ (Q) in Table 4. Therefore, an EPQ calculation must be performed before calculating the maximum inventory. To determine the EPQ value, the following formula is used:

EPQ $(Q)=\sqrt{ }(2 D S /((1-d / p) H)) \quad($ equation 3)

with :

$\mathrm{D}=$ demand per periode $\mathrm{S}=$ set-up cost per unit

$\mathrm{P}=$ production rate per periode $\mathrm{D}=$ demand rate per periode

$\mathrm{H}=$ holding cost per periode

From the calculation based on the formula, the results of the calculation of inventory targets are obtained as follows Table 3

Design and Development of Decision Making Systems After the data collection and processing is completed, the next model design and decision making system for inventory control and production scheduling is carried out to make the reorder process automated and produce optimal scheduling decisions. This is caused by large product variants, limits on production capacity,

C. Limits on Warehouse capacity, and work priorities.

The initial step in making this tool is to do a conceptual description of the current condition to find out the relationship between the entities involved in the process of inventory control PT. Mortars (data flow, process flow, as well as appropriate forms of repair if needed). Figure 1 shows data flow diagram of the process of inventory control and production scheduling of PT. Mortars. In the current condition, the process of inventory control and production scheduling is done manually, there is no optimization and automation process.

This research can be an option and a solution to improve inventory parameters and inventory control mechanisms (reorder systems) at PT. Mortars. In the reorder process that is designed with a linear programming approach, there are 
The $1^{\text {st }}$ International Conference on Business and Engineering Management (IConBEM)

February $1^{\text {st }} 2020$, Institut Teknologi Sepuluh Nopember, Surabaya, Indonesia

limits on production capacity and storage capacity. Production capacity will depend on the allocation of production time, while storage capacity is the difference between inventory levels and maximum storage capacity (warehouse capacity). The number of reorders should be smaller equals than the allocation of production time and remaining storage capacity, so not all reorders can be scheduled.

The process of allocating production time is done by calculating automatically using Excel formulations. The formulation to determine the allocation of production time is determined by selecting the closest working hour mode, under the allocation of hours needed to re-order using the function $=$ IF. The working hours are Monday to Friday in normal working hours are 16 hours, 19 hours long shift (1 shift overtime) or 22 hours long shift ( 2 shifts overtime). While for Saturday and Sunday, there will be options of overtime from 4 hours, 8 hours, 12 hours, 16 seconds.

Linear programming modeling is made with the objective function to minimize the total weighting- priority of reorder. The weighting-priority is the multiplications between the Q optimal (optimization results) with the priority level for each product. The greater the reorder priority, the smaller the weighting- priority value will be. This is intended so that products with a higher degree of urgency will be prioritized for production, so there is no shortage of products. Thus, the service level value can be improved.

Figure 2 shows an example of a production scheduling decision flow diagram using linear programming modeling and the periodic review system $(\mathrm{R}, \mathrm{S})$ method. Below is the linear programming formulation of the program: Objective function: hours, 19 hours or even 22 hours.

$\operatorname{Min} \mathrm{Z}=\sum^{n} W_{R J} \cdot Q_{R J} *($ Equitation 4$)$

The objective-function is intended so that production scheduling matches the priority scheduling weighting $\left(W_{R J}\right)$. The weighting is calculated based on consideration of urgency weight and quantity weight. Urgency weighting is the initial weighting given to urgent products that have an inventory level below demand. This is intended to prevent product shortages so that service levels can be maximized. If all urgent products havebeen scheduled, then the scheduling priority will conduct based on production quantity to reduce the number set-up (quantity weights). Storage capacity limits: With:

$Q_{R J}=$ the number of reorder quanity $\mathrm{J}(\mathrm{J}=1,2, . . \mathrm{n})$

$S_{R J}=$ order up to level or maximum stock $\mathrm{J}(\mathrm{J}=1,2, \ldots \mathrm{n})$

$I_{R J}=$ the number of inventory level $\mathrm{J}(\mathrm{J}=1,2, . . \mathrm{n})$

$d_{R J}=$ the number of demand quantity $\mathrm{J}(\mathrm{J}=1,2, . \mathrm{n})$

$W_{R J}=$ production priority level $\mathrm{J}(\mathrm{J}=1,2, . . \mathrm{n})$

$B_{V}$ = remaining storage capacity (bag)

$A_{T J}=$ time needed to produce 1 product $\mathrm{J}$

$B_{T} \quad=$ allocation of production time (hours)

$Q_{R J}{ }^{*}=$ optimum production quantity of product $\mathrm{J}(\mathrm{J}=1$, $2, . \mathrm{n})$

Modeling is made as part of the process of optimizing decision-making support tools. System support process optimization is needed in the form of data sources, data processing, systems and interfaces to carry out the functions of decision-making support tools. Figure 3 is a system and process flowchart of decision-making support tools that have been made: $n$

$Q_{R J} * \leq B_{V},(\mathrm{q}=1,2, \ldots \ldots \mathrm{m}) \ldots \ldots$ (equitation 5$)$

This limitation is intended so that the final result Figure 3. Production Scheduling System and Process of scheduling does not exceed the available warehouse capacity. Limitation of production time allocation: Before running the optimization process, it takes data in the form of demand data, production data and

$\stackrel{n}{n}$

$j=1 A_{t J} \cdot Q_{R J} * \leq B_{T},(\mathrm{r}=1,2, \ldots, \mathrm{m}) \ldots \ldots$ (equitation 6$)$

This limitation is intended so that production shipping data. The data is available on the ERP system owned by PT. Mortars. After the data is extracted from scheduling does not exceed the allocation of production time. There are 3 choices of working hours allocation: normal, long shift, and Saturday or Sunday overtime. Limitation on optimum order quantity: ERP into data with the Ms. Excel format, the data must be copied into the template provided. Then, select the desired date, for the system will work according to the selected date only. Then, the system will process data into

$$
{ }_{j=1}^{n} Q_{R J} * . \leq Q_{R J},(\mathrm{q}=1,2, \ldots, \mathrm{m}) \text { (equitation 7) }
$$

This limitation is intended so that the results of inventory level information, the number of reorder requirements, production time requirements and priority

production scheduling do not exceed the specified order up to level or maximum stock. weights automatically

To run the optimization process, the solver add-ins function must be activated so that a dialog box will appear with the display shown in Figure 4. From the picture, there are columns for setting the objective function (set objective) and constraints of the modeling that has been made. The column must be filled in accordance with the template and modeling made. The process of running the Solver program is done by selecting the method of solving (select solving method), select the Simplex LP method. Then press the solve button, and the program will run automatically calculates the optimal order back for each product.

After the process of running the Solver program, reorder quantity for each product will be resulted in the most optimal combination. These results obtained in accordance with the method, modeling, objective functions and constraints used in the supporting tools that has been designed (can be seen in Figure 5 production schedule column). If the results is optimal, the process has been completed and a production schedule can be published. Figure 6 is an example of a dialog box for optimal conditions.If it does not produce the optimal order quantity, an evaluation must be made to the cause of the failure. The evaluation process can be done by reading the reports in the dialog box which show the cause of not getting optimal results. Figure 7 is an example of a dialog box when no optimal solution is obtained. By pressing reports (red circle) in the dialog box in Figure 7, there will be a report about the causes of the not optimum result, as shown in figure 8:

To prove that the designed tool is capable of producing the right decision, a numerical test is then performed by comparing the optimization results using the tool that has been designed with manual calculations. Date 01/31/2019 was chosen as a sample numerical test date with the calculation results as in table 5 . 
The $1^{\text {st }}$ International Conference on Business and Engineering Management (IConBEM)

February $1^{\text {st }} 2020$, Institut Teknologi Sepuluh Nopember, Surabaya, Indonesia

Table 5 shows the updated inventory level information and the number of re-orders. The total need for production hours is 31.6 hours, so not all products can be produced, but production can be done with an allocation of 22 hours of production hours. Products that must be produced because the level of supply is less than consecutive demand are: MR-40240KG (1), MR-301-40KG (2), MR-440-50KG (3), MR-480$25 \mathrm{KG}$ (4), MR-101-40KG (5). The need for production hours for all products is 8,1 hours. So that there are 15.9 production hours remaining, which will be used to produce products with the largest re-order quantity, MR-302-50kg (6), MR- 400-25kg (7), MR-380-40kg (8), etc. If the results of the manual calculation in table 5 are compared to the results of optimization with the tools in figure 5, both results are match and the tools can be declared valid.

The next step is to simulate inventory control to find out the total cost and service level produced by each method so that it can be known which method is suitable for application. Simulation results for each method with demand data in the first quarter of 2019 can be seen in Table 6 to Table 8

From Table 6. it can be concluded that in the January period, the method $(\mathrm{R}, \mathrm{s}, \mathrm{S})$ produced the highest service level up to $100 \%$. The method $(\mathrm{R}, \mathrm{s}, \mathrm{S})$ is able to produce a higher sevice level $1.95 \%$ compared to the existing method. In terms of cost, the method $(\mathrm{R}, \mathrm{S})$ produces the lowest total cost of $\mathrm{Rp}$. 373. 592. 841. Method ( $R, S)$ is able to produce cost savings of Rp. 5,427,636 compared to the existing method.

From Table 7. it can be concluded that in the February period, the method $(\mathrm{R}, \mathrm{s}, \mathrm{S})$ still produced a service level value of $100 \%$. The method $(\mathrm{R}, \mathrm{s}, \mathrm{S})$ becomes the method with the highest service level and results $1.25 \%$ higher sevice level compared to the existing method. In terms of cost, the method (R, S) still produces the lowest total cost of Rp. 380. 879. 204. Method $(\mathrm{R}, \mathrm{S})$ able to produce cost savings of $\mathrm{Rp}$. $5,907,775$ compared to the existing method.

From Table 8. it can be concluded that in the March period, the method $(\mathrm{R}, \mathrm{s}, \mathrm{S})$ produced a service level value of $99.80 \%$ and a total cost of Rp. 396,083,069. The method (R, s, S) becomes the method with the highest service level and the lowest total cost. This method results in a $1.25 \%$ higher sevice level and a cost savings of Rp. 5,270,329 when compared to the existing method.

\section{CONCLUSION}

From Table 9. It can be concluded that in the Q1 2019 period, the overall method $(\mathrm{R}, \mathrm{s}, \mathrm{S})$ produced the highest service level value of $99.93 \%$ with a product shortage of (834) bags. This value is $1.29 \%$ higher than the existing method with a service level of $99.59 \%$ and product shortages $(4,963)$. The service level in the method $(\mathrm{R}, \mathrm{s}, \mathrm{S})$ is $0.34 \%$ higher than the method $(\mathrm{R}, \mathrm{S})$ which produces a service level of $98.64 \%$ and a shortage of products $(16,648)$.

Product shortages in existing methods and $(\mathrm{R}, \mathrm{S})$ methods are dominated by the skimcoat product type that is only produced once a week. Inventories of skimcoat products have been exhausted before the next production period, this is due to the factor of an increase in the amount of demand that is greater than the safety stock. While this does not occur in the method $(\mathrm{R}, \mathrm{s}, \mathrm{S})$ because the skimcoat product can be produced every day if the inventory level is below the reorder point.

The existing method becomes the method with the lowest set-up cost when compared to the $(\mathrm{R}, \mathrm{S})$ and $(\mathrm{R}, \mathrm{s}, \mathrm{S})$ methods. The set-up cost in the existing method is Rp. 61,938,062, save more Rp. 1,696,370 compared to the methods (R, S) and Rp. 5,989,485 compared to the method $(\mathrm{R}, \mathrm{s}, \mathrm{S})$. The set-up cost is influenced by the frequency of product change and skimcoat cleaning frequency.

The existing method and (R, S) method produced 587 times and 607 times set-up number. The method (R, s, S) produces much lower set-up number with only 298 times (almost 50\% compared to other methods). This is because the method ( $R$, $\mathrm{s}, \mathrm{S}$ ) has 2 inventory parameters namely reorder point (s) and maximum inventory $(\mathrm{S})$, so production will only be carried out if the review period has arrived and the inventory level is less equal than the reorder point so the amount reorder will be optimal according to EPQ. Whereas in the existing method and method $(\mathrm{R}, \mathrm{S})$ when the review period has arrived, reorders must still be made even though the number of re-orders is less than EPQ. The number of re-orders will have an impact on the set-up frequency.

Although the method (R, S) has a smaller number of product changes, the set-up costs obtained do not have a significant difference when compared to the existing method and method $(\mathrm{R}, \mathrm{S})$. In the method $(\mathrm{R}, \mathrm{s}, \mathrm{S})$ skimcoat product replenishment can be done every day, this will have an impact on the cost of skimcoat cleaning in every changeover of plastering and adhesives products to skimcoat products.

The method $(\mathrm{R}, \mathrm{S})$ obtained the lowest inventory cost of Rp. $304,134,294$. The inventory cost is Rp. 17,965,505 lower than the existing method and Rp. 5,469,796 lower when compared to the method $(\mathrm{R}, \mathrm{s}, \mathrm{S})$. The amount of inventory costs will be influenced by the average of inventory amount that is owned every day. This is in line with the average inventory method $(\mathrm{R}, \mathrm{S})$ which is lower when compared to the other methods.

The amount of processing costs and the cost of inventory deviations will influenced by the production amount (the number of requests for each method is the same). If the production amount is less than the amount of demand, automatically the amount of ending inventory will be less than the initial inventory.

The existing method produces the lowest processing cost, which is Rp. 764,488,302. The process cost of existing method a little more efficient when compared to the method $(\mathrm{R}, \mathrm{s}, \mathrm{S})$ in the amount of Rp. 159,004 and Rp.7,588,434 less than the $(\mathrm{R}, \mathrm{S})$ method. The higher process cost in the method $(\mathrm{R}, \mathrm{S})$ is influenced by the initial inventory method $(\mathrm{R}, \mathrm{S})$ which is lower than the other methods. Although the existing method has a lower processing cost than the $(\mathrm{R}, \mathrm{S})$ method, this method has an higher inventory deviation Rp. 6,450,119 than the method (R, S). Likewise Method (R, s, S) which has an higher inventory deviation cost Rp. 13,161,658 compared to the methods $(\mathrm{R}, \mathrm{S})$

Overall the lowest total cost obtained by the method $(\mathrm{R}, \mathrm{S})$ with a value of Rp. 1,152,029,693. The total cost is Rp. $15,130,801$ more efficient compared to the existing method and Rp. 15,579,454 more efficient compared to the method $(\mathrm{R}, \mathrm{s}, \mathrm{S})$. So it can be concluded that the method $(\mathrm{R}, \mathrm{s}, \mathrm{S})$ is the best method in producing the highest service level, while the method $(\mathrm{R}, \mathrm{S})$ is the best method in producing the lowest total cost. 
The $1^{\text {st }}$ International Conference on Business and Engineering Management (IConBEM)

February $1^{\text {st }} 2020$, Institut Teknologi Sepuluh Nopember, Surabaya, Indonesia

\section{REFERENCES}

[1] L. I. Nicolae, D. Tanasescu, and V. Popa, "Customer Expectations Management," Valahian J. Econ. Stud., vol. 4, no. 3, pp. 91-100, 2013.

[2] M. Gansterer, "Aggregate planning and forecasting in make-to-order production systems," 2015, doi: 10.1016/j.ijpe.2015.06.001.

[3] I. N. Pujawan and E. Mahendrawathi, "Supply Chain Management." Penerbit Andi, Yogyakarta, 2017.

[4] F. M. Takey and M. A. Mesquita, "Aggregate Planning for a Large Food Manufacturer with High Seasonal Demand," Brazilian J. Oper.
Prod. Manag., vol. 3, no. 1, pp. 05-20, 2006.

[5] E. A. Silver, D. F. Pyke, and D. J. Thomas, Inventory and Production Management in Supply Chains, 3rd ed. John Wiley and Sons, 1998.

[6] J. Heizer, B. Render, and C. Munson, Operations Management, 10th ed. New Jersey: Pearson Education Inc, 2011.

[7] R. B. Chase, F. R. Jacobs, and N. J. Adequilano, Operation Management for Competitive Advantage. New York: McGrawHil/Irwin, 2006. 